\title{
O EXERCICIO DA PROFISSÃO MEDICA
}

POR BENEDICTO DA CUNHA CAMPOS

O assumpto que nos traz á vossa presença se enquadra no ambito dos que interessam, de um modo inconfundivel, a clesse academica, por isso que ella, hoje ainda não exposta ás vicissitudes da labuta diaria, amanhã se verá a bracos com um sem numero de luctas, que, para vencel-as, muito esforço, muita abnegação, e muito patriotismo serão necessarios.

A muitos ha de parecer extranho que tratemos de assumpto de tão grande e tão complexa importancia; hão de nos negar autoridade e competencia para emittirmos um juizo a esse respeito; hão de nos taxar de imprudentes, de pretenciosos, e quiçá mesmo de insensatos por nos abalançarmos a invadir a seára dos nossos superiores.

Aos que assim pensarem, aos que em nossas palavras despreten-. ciosas descobrirem e interpretarem aquillo que em nosso cerebro nunca existiu e por que nosso coração nunca palpitou, aos que tiverem a coragem de negar á mocidade o direito, que a ninguem se nega, de dar expansão, de um modo sincero e sem rebuços, ás aspirações de seus ideaes, nunca dobrados á conveniencia de interesses subalternos, diremos que a nossa vida, soibre cuja marcha ainda não soprou o vento das paixões que dominam o espirito e ferem a consciencias dos que, o peso das injunções tornou seus escravos, exige de nós sacrificios immensos, um retemperamento continuo de nosso caracter, para que não pereça, de envolto com o tumulto das luctas futuras, a sagrada scenteiha que animou nossos esforços e que impediu morressem nossas esperanças.

Não se amolda na quinta essiencia dos nossos sentimentos, a mais leve e a mais subtil idea de um nacionalismo ferrenho e acanhado, ante o qual só o que é nosso é que vale, e só é nosso, exclusivamente nosso o que existe em nossa Patria. Não. Não ha semelhante despotismo $\mathrm{n}_{\mathrm{a}}$ alma da mocidade; não ha essa egolatria adulterante e mesquinha. A mocidade brasileira, educada num ambiente onde em tudo resplandece e fulguṛa a liberdade, que é o consolo, a esperança e a garantia dos que em sua Patria procuram agasalho; instruida num circulo de relações onde o esforço e o animo dos que lhe aprimoram e revigoram o espirito, nadam em correntes sadias de ideaes da mais requintada liberdade, é, por natureza, traz por assim dizer, vinculada na cellula mater que lhe deu origem, a magnitude de seus sentimentos, vastos em franqueza e profundos em liberalismo.

Seja pois permittido aos moços, sobre cujos hombros pesarão dentro em breve as responsabilidades immanentes á profissão que 
abraçaram, levantar sua voz neste recinto, onde se calam os ideaes de almas irmanades pela mesma fé, alimentadas pelo mesmo enthusiasmo, para, defendendo seus interesses futuros, dizer bem alto e bem claro, certas verdades que carecem de ser assoalhadas, pois talvez assim encontre écho na consciencia dos culpados!

"A profissão medica, - dizia o inolvidavel prof. Oscar Freire, em sua lição inaugural de DEONTOLOGIA MEDICA, realisada em 1921 na Faculdade de Medicina e Cirurgia de São Paulo, onde pontificára com brilho e valor raros, - padece nos centros mais adiantados do paiz, como algures, uma crise moral e material, que dia a dia mais clara se define e se accentua.

O phenomeno é universal e de ha muito assignalado em outros paizes. Depende naturalmente das condições intellectuae $e_{S}$ e moraes do mundo occidental.

A loucura collectiva, que durante quatro annos empolgou num delirio sanguinario os povos mais cultos do globo e, ainda mais, o cruel e desmesurado utilitarismo, que nos ultimos annos, vem avassalando os meios da mais elevada cultura, arrastaram espiritos de mais fino quilate a proclamarem a fallencia da humanidade"

$\mathrm{E}$ desse embate que se travou forte entre adversarios fortes, resultou, para vencedores e vencidos, condições de abatimento moral, de desequilibrio organico de forças e de anniquilamento consideravel de reservas matieriaes. A vida, na mais modesta das suas exigencias, se modificára de tal forma, de tal forma se aggravaram as necessidades que, para muitos, a unica salvação foi procurar longe da Patria, outróra rica e dadivosa, os proventos para a sua manutenção.

E a immigração dos elementos dos paizes belligerantes se fez para as Americas em proporções assombrosas.

O Brasil sentiu forte, essa carreação do elemento extrangeiro, ávido e esperançoso de, com o seu trabalko, prover as exigencias de suas vidas.

Ao lado do immigrante que se destinava aos nossos campos, ás nossas lavouras, ás nossas officinas, um numero bem apreciavel de profissionees procurava se collocar nos centros mais adiantados do paiz, nas melhores cidades e pelo interior dos grandes Estados ameaçando-nos de uma verdadeira plethora profissional.

E para São Paulo, como vós todos bem sabeis, mais intensa, mais frequente e mais heterogenea se mostrou essa preferencia. Não precisamos justificar a essencia dos motivos dessa escolha, que, por demais sabidos, lembrados agora não se faz mistér.

E São Paulo que, como defensor do liberalismo e do nacionalismo bem comprehendidos, pode ser tido como um exemplo, se em parte se beneficiou com essa preferencia, por outro lado, encarado sob o prisma, para muitos pouco attrahente, da cultura e da 
conservação de seus principios de moral e de civismo, sente que a pouco e pouco se moddifica o ambiente onde se entrechocam as idéas e os interesses de seu filhos, com os interesses e as idéas de seus hospedes.

E' que a concorrencia, sobre ser grande, o que em hypothese alguma, se fosse honesta e leal, seria de se desprezar, é desleal, é, perdoae-nos o termo, vergonhosa, para não dizermos immoral.

A concorrencia, maximí na profissão medica, e principalmente em São Paulo, dos profissionaes extrangeiros, se outro valor não possuisse, $\mathrm{n}_{\mathrm{a}}$ hypothese infelizmente pouco verificavel, de ser feita por elementos de escól sobre o duplo ponto de vista moral e scientifico, serviria ao menos para estimular os naciones, para nelles despertar a scentelha viva do seu valor, a necessidade imperiosa de não se deixar vencer, reascendendo dessa forma, em suas almas, a chamma ardente da nacionalidade até então bruxoleante por falta de estimulo e de enthusiasmo.

Infelizmente, meus collegas, salvo raras e honrosissimas excep̧̧ões, bem outra é a natureza, bem outra é a qualidade do elemento extrangeiros que demanda a nossa Capital e se infiltra pelo interior do nosso Estado.

E eis a razão de ser de minha presença nesta tribuna, para protestar em nome de meus collegas de São Paulo, amanhã medicos, contra esse estado actual da infiltração de profissionaes extrangeiros. a muitos dos quaes faz falta, já não diremos apenas a competencia profissional que era de se exigir de todos, mas um pouco de idoneidade moral, um laivo ao menos que fosse de educação e de respeito ao que é nosso e ao que nos é caro.

$\mathrm{E}$ pensar-se meus collegas, que tudo isso, que todo exse descontentamento que nos compunge e nos contrista o coração, mas que em hypothese alguma avassala a nossa energia e apathisa a nossa vontade, reside, - e nesta confissão vai um pesar immenso, - na exaggerada e descabida liberalidade com que, na opinião de Oscar Freire, “desequiparamos o medico extrangeiro do nacional, dispensando-o das provas mais trabalhosas de capacidade profissional e moral, que a lei teve por melhores na habilitação dos que se destinam a exercer a medicina".

Essa liberalidade das nossas leis, talvez já fôra admissivel em tempo quando as nosses faculdades, em numero de duas, não podiam supprir as necessidades do nosso paiz; hoje, porém, que nada menos de nove escolas medicas, entre officiaes e equiparadas, contribuem, cada anno, com algumas centenas de medicos, essa liberalidade 6 injustificavel e carece de ser diminuida, para não acarretar, como c está fazendo, prejuizos decorrentes dessa concorrencia desenfreada e sem limites. 
Passemos uma rapida revista pelos dados que nos fornece o Serviço Sanitario de São Paulo, sobre a porcentagem dos medicos extrangeiros existentes no Estado até o anno de 1920: MEDICOS EXTRAINGEIROS: 200, num total de 1369 medicos.

De 1920 até esta data esse numero tem augmentado e não erraremos se orçal-o para mais de duzentos e cincoenta (250). E nesse total se encontram poucos profissionaes que se submetteram ás provas exigidas pelo artigo 232 paragrapho $2 .^{\circ}$ do Reg. do Departamento Nacional da Saúdie Publica. Muitos delles foram dispensados dessa formalidade legal e moralisadora ou porque de facto possuissem titulos authenticos e valiosos de professores de universidades ou de escolas medicas extrangeiras, ou porque possuissem titulos que nós, na nossa boa fé $\Theta$ lastimavel ingenuidade, julgamos ter muito valor, representem grande competencia, quando na verdade nada mais são de que titulos fornecidos a granél, a quem os solioitar, verdadeiros titulos de expontação, sem importancia alguma no seu paiz e, honrosos, importantes e garantidore ${ }_{S}$ de regalias enormes no nosso! Nesse caso estão os titulos de livres docentes de muitas escolas medicas extrangeiras, titulos esses, aqui valiosos, lá, sem a minima importancia, doaveis aos que satisfizerem exigencias minimas, e que, em hypothese alguma, deveriam ser acceitos como inclusos nos que o $\S 3 .^{\circ}$ da Lei que regularisa o exercicio da medicina no Brasil, houve por bem exigir dos profissionaes extrangeiros.

Nada mais eloquente do que os numeros que nos fornece a estatística feita pelo Serviço Sanitario de São Paulo, sobre a porcentagem pertencente a cada escola medica brasileira na revalidação dos diplomas de profissionaes extrangeiros. Dentre os 200 que revalidaram exames no Brasil, 27 o fizeram pela Faculdade de Medicina da Bahia; 7 pela de Porto Alegre; 113 pela do Rio de Janeiro; 6 pela de S. Paulo; 34 pela Salude Publica do Rio, e os restantes pelo Instituto Hahnemanniano do Brasil (1), pela Junta Central de Hygiene (4); 2 pelo Governo de São Paulo, independente de exame, pela prova de qualidade de professor em estabelecimento extrangeiro officialmente reconhecido no respectivo paiz e quatro sem referencias exactas.

Dessa estatistica resalta logo um facto evidente e é o da pequena porcentagem dos medicos que procuram a Faculdade de Medicina de São Paulo para nella revalidarem seus titulos.

Desde sua fundação, ha 11 annos, inscreveram-se na Faculdade de São Paulo, para esse fim, 19 profissionees, de nacionalidades diversas, inclusive alguns brasileiros. Desses 19 apenas 13 fizeram as provas exigidas $\mathrm{e}$, desses 13,9 apenas conseguiram approvação. Dentre os reprovados contam-se 2 brasileiros. 
E o facto de ser pequena a porcentagem dos medicos que procuram a Escola Paulista para revalidação de seus titulos, fala bem alto do modo rigaroso $\theta$ severo como alli se realisam essas provas.

E' que os profissionaes paulistas sabem muito bem, melhor do que os seus collegas de outros Estados, por experiencia propria ou por conhecimento justo, do prejuizo enorme que causariam á sua classe se usassem de benevolencia nos seus julgamentos. Maior seria o numero de profissionaes extrangeiros que demandariam o Estado de S. Paulo; maior seria a concorrencia desses elementos, concorrencia que como já dissemos, não se recommenda de nenhuma forma pelo modo como ella é feita.

As consequencias dessa benevolencia no julgamento desses profissionees, vão se fazer sentir, mais do que em qualquer outro ponto do paiz, em São Paulo, para onde, em grande maioria, para não se dizer em quasi totalidade, se dirigem esses elementos. E é natural e explicavel mesmo que, não se sentindo os prejuizos dessa medida benevola em excesso, não se pense em por de lado o sentimentalismo ao se julgar esses profissionaes.

Estas minhas considerações não visam estabelecer um termo de comparação entre o que em São Paulo se faz, e o que se pratica no resto do Brasil. Não. O que vișamos é apenas focalisar ante vossos olhos, sem exaggero e sem bairrismo algum, o mal que se faz, não digo a São Paulo, mas ao Brasil inteiro favorecendo essa invasão.

Defendendo a causa de São Paulo, não defendemos apenas a causa paulista, defendemos a causa de vós outros que, com todo o direito e justiça amanhã vos dirigineis para lá, e, mais cedo ou mais tarde, sentireis as consequencias funestas desse nosso liberalismo, quando, na lucta pela vida, tiverdes deante de vós, collegas que não hesitam em lançar mão dos meios os mais degradantes e vergonhosos para vencer; collegas que cifram sua gloria em actos que aberram dos mais comesinhios principios de ethica i profisstional; collegas que se alegram em desacreditar e desmoralizar o que é nosso. - E então haveis por certo de dizer que não eramos bairristas, apaixonados e injustos!

Meditem, pois, os que têm sobre seus homibros a tarefa de julgar de capacidade profissional dos medicos extrangeiros, pensando no mal enorme que fazem usando de benevolencia para com elles. Quando merecedores, de facto, dos direitos que lhes outorgam as nosses leis não se lh'os negue; mas, no julgamento, não se deixem levar por criterios outros que não sejam os decorrentes da capacidade profissional por elles apresentada.

Assim procedendo por certo hão de concorrer para a elevação sempre maior do nivel scientifico e moral da classe medica brasileira, digna, pelo seu passado dos maiores respeitos; credora, pelo seu 
presente dos maiores elogios e, cujo futuro, amparado pela dignidade e pelo valor de seus representantes, não desmerecerá das esperança que nelles depositam os seus superiores.

E onde e quaes as medidas possivieis de modifficar essa liberalidade?

0 artigo 232 do Decr. 16.300 de 31 de Dezembro de 1923, estabelece:

"Só sená permittido o exercicio da medicina em qualquer de seus ramos e por qualquer de suas formas: 1) aos que se mostrem habilitados pelas escolas medicas officiaes ou equiparades na forma da lei; 2) aos que sendo graduados por escolas ou universidades extrangeiras, se habilitarem perante as faculdades brasileiras, na forma dos respectivos Regulamentos; 3) aos que sendo professores de universidades ou escolas extrangeiras, ou requererem ao iDepartamento Nacional da Saúde Publica. Esta permissão só será dada á vista de documentos devidamente authenticados, e quando no paiz a que essas universidades ou faculdades pertençam, gosarem de favor identico os professores das faculdades ibrasileiras".

Como vemos, as nossas leis não cogitam de saber, como se fazem em muitos paizes, por exemplo, na Belgica, se o portador do titulo possue ou não idoneidade moral; admittem religiosamente que todos elles a possuem. E' um excesso de generosidade prejudicial e inconveniente para nós, valiosio e convenientissimo para elles.

Deixemos, porém, de lado essa face da questão á qual não se pode negar valor; sua solução é difficil pois os defeitos da moral, fugidios e subtis, se escondem, ás vezes nos colleios de uma attitude apparentemente nobre e distincta.

Encaremol-a apenas sob o ponto de vista da capacidade profissional, pois essa é a prova flagrante e insophismavel, cuja realidade não se disfarça e não se esconde em eventuaes e estudados artificios de graça e de gentileza.

Esta prova, que seria o dique intransponivel onde se debateriam as aptidões aguilhoadas pelo preparo e julgadas pela consciencia de nossos profissionaes; esta prova que seria a segurança inilludivel de que os nossos juizes não se deixaram manear pelas apparencias muitas vezes fallazes, dos titulos espalhafatosos, dos reclamos estupefacientes, dos empenhos politicos; esta prova que seria, em ultima analyse, a unica fortaleza intransponivel, capaz de salvaguardar o interesse dos filhos do paiz; a garantia severa do futuro criterio scientifico e moral desses profissionaes; esta prova 
está, Infelizmente, e não sou eu quem vos diz, são os factos de cada dia que nos evidenciam esta opinião, relegada á segunda plana, porisso que os candidatos a ella munem-se antes das vaccinas preventivas e curativas contra as possiveis reprovações.

'E' triste, é desolador, é iniquo e é criminoso o procedimento desses elementos nacionaes que a politica tornou importantes, e que não titubeiam em recommendar a quem não conhecem e solicitar favores, que aos nossos, felizmente, nunca se concedeu, para que esses individuos se locupletem de nossa riqueza, se riam de nossa bôa fé, escarneçam do nosso desleixo e se vangloriem de suas expertezas.

E' esta, infelizmente, a situação em que nos encontramos deante do problema da habilitação dos medicos extrangeiros no Brasil. Em vez de se procurar, por todos os meios licitos, fazer uma selecção dentre os profissionaes extrangeiros que nos procurem, abrem-se-lhes as portas da vida clinica, entoam-se-lhes laudatorios, sem nem de leve se meditar que o nosso povo, tendo ainda em evolução a sua nacionalidade e o seu caracter, sentirá, forçosamente o influxo desse contacto, e em vez de se aperfeiçoar, de ter o estimulo das bôas acções, estacionará, se não regredir.

A selecção intellectual dos medicos extrangeiros é um problema de alta complexidade. Sua solução deve merecer dos que governam cuidados immediatos.

O ideal seria cercear quasi que em absoluto essa concessão; concedel-a apenas aos profissionaes de reconhecida competencia, professores de escolas medicas de valor inconteste e quando no paiz a que essas escolas pertencessem, identicos direitos coubessem aos professores de nossas faculdades. Mas esse principio de defeza honesta e regular dos nossos direitos, collide com o espirito liberalissimo de nossas leis.

o mal que actualmente advem do liberalismo mal applicado de nossas leis se transformaria em bem, desde o dia em que os nossos homens de governo, aos quaes se commette o poder de fiscalisar a sua applicação, se compenetrassem firmemente de seus deveres, e não os deixassem vagar á mercê das situações politicas quando não de interesses inconfessaveis.

Mas, mesmo com o liberalismo de nossas leis, muito mais do que se tem feito pode-se fazer. Cumpra-se o que a lei exige; cada juiz, na sua consciencia não procure adulterar a essencia e o espirito do legislador. Exija-sse do candidato á revalidação de diploma, provas insophismaveis de sua competencia profissional; sejam elles julgados com criterio, mas não se lhes conceda benevolencia; não se lhes procure desculpas de não conhecerem ou de conhecerem mal a nossa lingua. Se os nossos quasi sempre, se julga com rigor, porque razão ser-se complacente com os extranhos? E ainda mais: quem 
nos garante o que nos reserva para o futuro essa corrente immigratoria intensa de profissionaes extrangeiros?

Necessidade de seu auxilio profissional, não o é por certo, porisso que a maioria dos que immigram, via de regra, são de capacidade profissional bem inferior á dos nossos.

Necessidade do influxo de seus sentimentos moraes, tambem não o é, poị nós os cultivamos e não ha necessidade que os modifiquemos.

E é facto sabido por todos que a causa determinante dessa continua e cada vez mais intensa immigração, reside nas difficuldades economicas dos paizes de origem desses profissionaes, quiça mesmo, em maior gráu, na falta de cơmlpetencia profissional alliada a um espirito de aventureiro sedento de riquezas; é tamibem do dominio de todos que o affluxo sempre continuo e crescente desses profissionaes é amparado e estimulado pela 'excessiva e descomedida liberalidade de nossas leis.

Urge pois que se morallise essa liberalidade, já que não está no espirito e na indole de nosso povo cercear, como muitos paizes o fazem, essa liberdade aos extrangeiros. Que haja liberalidade nessa e em outras questões; mas não abdiquemos nunca da necessidade de amparar essa liberalidade com o criterio de uma moral sempre elevada e de uma justiça nunca desmentida.

$\mathrm{O}_{\mathrm{S}}$ prejuizos da complacencia e do proteccionismo que se prodigalisam aos extrangeiros, sem distinção dos que por suas qualidades os merecem e dos que não os merecem por seus defeitos, são tantos e de gravidade tão grande, tanto no que se refere á pratica da medicina, quanto no que concerne á pratica da moral, que longo e fastidioso seria lemibral-os aqui.

Ao lado dos que a liberalidade das nossas leis concede identicos direitos aos dos medicos nacionaes, a injustiça residindo apenas na facilidade com que esses direitos são obtidos, outros ha que sã்o duplamente beneficiados. Beneficiados pela nossa benevolencia e beneficiados pela nossa bôa fé. Refiro-me a certos extrangeiros, portadores de titulos falsos, titulos imponentes e cheios de qualificativos, e que conseguem, não se sabe como, tornar-se evidentes, merecendo a comsideração e o respeito dos nossos.

E' do conhecimento de todos o caso do allemão Maximiliano Kröne, que se apresentou á Faculdade de Medicina do Rio com titulo concedido pela Universidade de Munich. A Congregação da Faculdade de Medicina do Rio, illudida em sua bôa fé pelo despudorado extrangeiro, concedeu-lhe permissão para exercer a clinica no nosso territorio. Esteve numa das cidades do Interior do Estado de São Paulo e o corpo clinico dessa localidade, desmascarou o emibusteiro, promovendo junto ás respectivas autoridades, o processo necessario, 
cuja solução foi o cancellamento da ordem para o meliante clinicar no Brasil. Na Allemanha, Kröne, rezam as informações officiaes, era um serralheiro.

Um' outro facto qú illustrai este mesmo assumptó a a averigualdo pela Directoria do Serviço Sanitario de São Paulo, sobre a origem do titulo concedido a R. B. Este individuo, sem nunca ter sahido de S. Paulo, muniu-se de um certificado de exames prestados perante a Universidade de.Padua, conseguindo, matricular-se na Faculdade de Medicina do Rio, onde em pouco tempo, o necessario para isso, terminou o seu curso. Diplomou-se a 13 de Dezembro de 1917 e a 2 de Janeiro de 1918, registou o seu titulo em S. Paulo. Clinicou nesse Estado por dois annos: foi dada denuncia ao Serviço Sanitario de que esse individuo era portador de um titulo falso. Feitas as averiguações, chegou-se á conclusão de que R. B. jamais fôra alumıno da Universidade de Padua, conforme declaração feita pelo Reitor dessa Universidade. E' mais um exemplo frisante de que a nossa bôa fé em relação ao elemento extrangeiro, corre parelhas com o liberalismo de nossas leis.

São typipos esses casos e não carecem de considerações de especie alguma para se concluir como andamos ás tontas nessa questão de revalidação de diplomas.

Ao nosso vêr, não param ahi as falhas nesse sentido. O Departamento Nacional da Saúde Publica concede, sob pretextos varios, licença para profissionaes extrangeiros clinicarem por 6 mezes, um anno e até mais, sem haverem preenohido as formalidades legaes, como sejam a revalidação de exames e o registo de seus titulos. E' um mal de consequencias lastimaveis, porisso que os beneficiados facilmente fogem ao cumprimento opportuno de suas obrigações.

A Directoria do Serviço Sanitario de São Paulo, deante da observação diaria desses factos, só permitte essa clinica de favor quando emanada ordem dos poderes superiores.

Acreditamos nada mais ser necessario juntar ao que acabamos de vos expor em defesa do assumpto que serviu de base á proposta que, em nome dos estudantes de medicina de São Paulo, tomamos a liberdade de fazer ao Congresso Inter-Estadual dos Estudantes de Medicina.

Meus collegas.

Em nome de meus collegas de São Paulo, como vós futuros apostolo do mesmo sacerdocio, cujas almas commungam diariamente com as vossas a sagrada hostia que encarna os deveres de uma mesma profissão, cujos corações de brasileiros palpitam de amor e vibram de enthusiasmo pela grandeza e pela honra de sue Patria, eu appello para a vossa enengia, eu conto com o vosso apoio no sentido de juntos trabalharmos na defesa honesta e justa dos nossos interesses, moralisando a liberalidade das nossas leis. 